This PDF is a simplified version of the original article published in Internet Archaeology. Enlarged images, and interactive features which support this publication can be found in the original version online. All links also go to the online version.

Please cite this as: Watson, S. 2021 Public Benefit: the challenge for development-led archaeology in the UK, Internet Archaeology 57. https://doi.org/10.11141/ia.57.1

\title{
Public Benefit: the challenge for development-led archaeology in the UK
}

\author{
Sadie Watson
}

\section{Summary}

The challenge of providing public benefit from development control archaeology has been a concern across Europe after both the Valletta and Faro conventions encouraged the view that the public must be the key beneficiaries of archaeological work, and since then the theoretical concept of public benefit has become well recognised across our profession. However, it seems to me that the archaeological sector does not yet provide this in a meaningful way or know how to maximise the public benefit potential of our work; indeed, this is acknowledged at the highest levels (e.g. British Academy 2017, 33).

The EAC established their Working Group on 'Making the Case' to investigate examples of best practice and provide a practical toolkit for the better articulation of public benefit arising from development-led archaeology (EAC 2019). In the UK the Chartered Institute for Archaeologists has published a briefing document that outlines the potential for public benefit offered by archaeology (CIfA 2020). This dovetails well with a new research project, funded by United Kingdom Research and Innovation (UKRI) and hosted at Museum of London Archaeology (MOLA), intended to ensure that public benefit is at the heart of decision-making throughout the development control sector in the UK (MOLA 2019). This article provides an introduction to the rationale behind this project and outlines how the project ambitions could be achieved through a careful navigation through the complex structures of development programmes' procurement and management.

\section{The Planning, Development and Construction Context}

As a practicing archaeologist working in the development-led sector since the mid 1990s, I have worked on many projects of all sizes, largely within the City of London where the archaeology is deep and complex. Logistical considerations and extensive truncation can complicate the programme and it has usually been the case that the 
archaeological works take place behind hoardings installed by the client, to shield the construction works from public view. Exceptions to this are rare but include the Bloomberg excavations undertaken by MOLA between 2011-2014, where the City of London Corporation included public provisions in the planning condition, ensuring a programme of activities was designed and provided during the fieldwork, and similarly large excavations at 8-10 Moorgate (also in the City of London), where public access was granted on specific days (Figure 1). The developers of The Stage, where Shakespearean theatre remains were anticipated, incorporated high-cost public-focused plans in the new development (MOLA 2018). Notably, this project has in turn encouraged further similar sites to consider their public benefit provision (see Davies and Single, this issue).

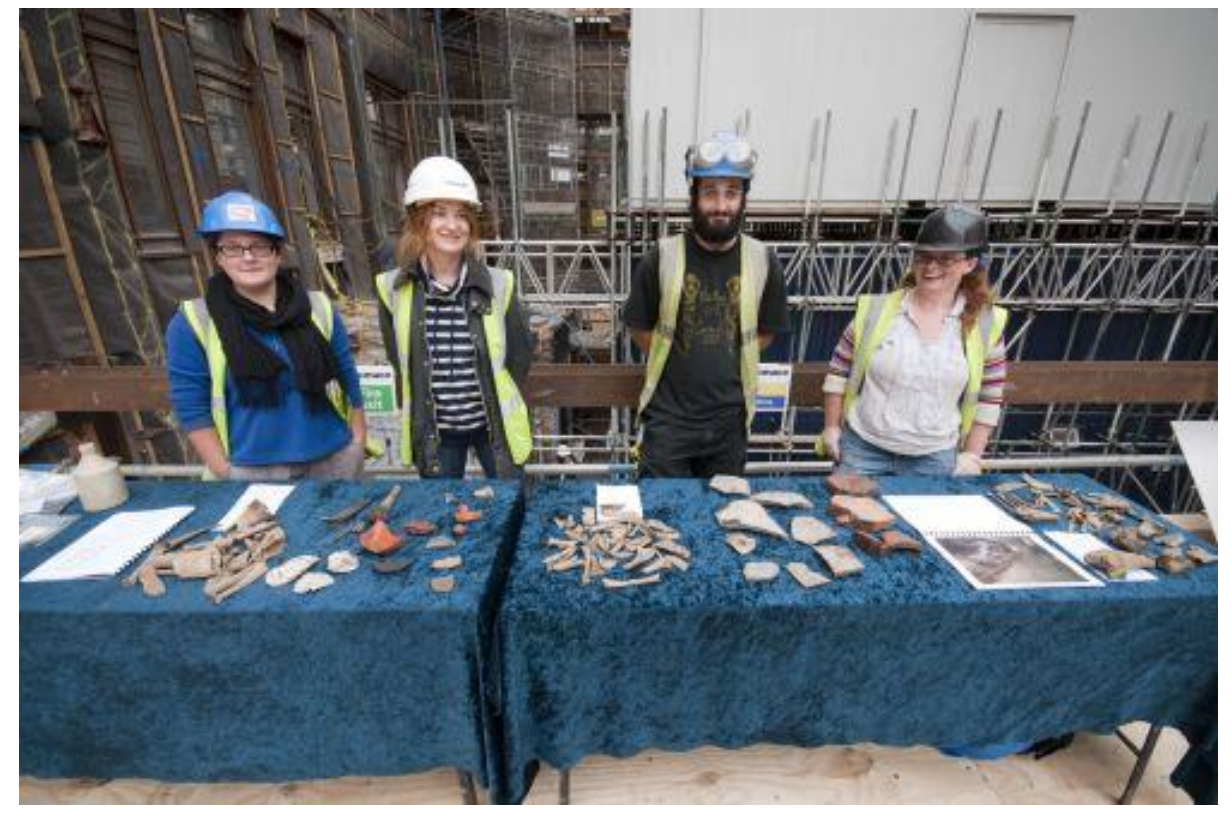

Figure 1: Archaeologists welcoming the public onto site at 8-10 Moorgate. Photo by Margaret Cox, MOLA

There are collaborative projects working to advance the provision of public benefit in the UK, both from within the sector (Wills 2018) and from central Government. The Department for Culture, Media and Sport (DCMS) have launched their Cultural Heritage Capital project (GOV.UK 2021), intended to provide a framework for policy makers and public spending plans to assess the potential for positive social impact in terms of the impacts on cultural heritage. This builds on a project led by the Department for the Environment, Food and Rural Affairs (DEFRA), intended to provide a framework for assessing the capital inherent in the natural environment (DEFRA 2020).

Cultural heritage is now acknowledged as a major provider of positive social impact (Pennington et al. 2019; Reilly et al. 2018), but the precise mechanisms for measuring and evaluating this are not yet established. The DCMS project is due to run for a decade and will only specifically relate to public spending projects, although this will also be hugely relevant to development-led archaeology, particularly those projects that are undertaken on publicly funded developments such as infrastructure. 


\section{The Potential (and obligation) with Infrastructure}

The infrastructure sector is one of the most significant funding streams for archaeology in the UK and is growing steadily (FAME 2020). Examples include roads, energy, air travel and, of course, rail. The proportion of funding from infrastructure is set to grow over the next few years owing to increased plans for transport infrastructure (GOV.UK 2020b), with total spends into the billions. These publicly funded infrastructure projects operate outside the usual planning regime, with development enabled through parliamentary bills, which in the context of the historic environment offer the opportunity to adapt regulations and methodologies to target specific research aims (HS2 Ltd 2017, 4-8). High Speed 2 is one such project, of a truly mammoth scale, with a total of 60 sites offering a 'once in a generation opportunity' (HS2 Ltd 2018). This project was established with an expectation that 'work will be focused on outcomes ... which will include real and substantive public benefit' (HS2 Ltd 2017, 2) but there is currently no robust way of specifying, assessing or measuring this. Projects that are funded by taxation are subject to evaluations set out in HM Treasury Green Book, which provides guidance on managing public money (HM Treasury 2018) by introducing the concept of economic appraisal of investment based on the principles of welfare economics or social value. Most aspects of major schemes such as HS2 and road projects are assessed using the Green Book criteria plus associated guidance in the Magenta Book, which outlines the appropriate evaluation steps and methodologies (HM Treasury 2020). Archaeology and the public funds spent on it are glaring omissions from this widely accepted and well-used evaluation process.

The lack of established evaluation procedures for development control archaeology stands in contrast to recent developments in the wider cultural and arts sector, which understands the need to provide assessments of impact and public benefit, specifically in relation to its value to individuals and society (Crossick and Kaszynska 2016, 159). Notably, within the Crossick and Kaszynska review and during background research into the value of the arts and cultural heritage there was very little mention of archaeology observed, despite the significant funding it attracts through the development-control system. The subsequent establishment of the Centre for Cultural Value (Leeds University 2020) is intended to influence cultural policy through rigorous research and evaluation. The focus for this is the arts, culture and heritage sectors, although again development-control archaeology was not well represented. I have the feeling this is due to our own reticence to explore beyond our own sectoral boundaries, and problems with our external communications rather than a rejection of our value by the wider cultural sector.

The UKRI proposal seeks to fill this gap by broadening communication between archaeology and other aligned disciplines. It will establish relevant and useful criteria, with the aim of positioning public benefit as the focus for future projects.

\section{The Challenge with Commercial Restraints}


A significant sticking point for any progress in the meaningful consideration of public benefit provision is likely to be the complex procurement and management structures common on major infrastructure projects, like the A14 improvement scheme (Figure 2) or HS2. On the HS2 project the clients are HS2, an executive non-departmental public body set up by Act of Parliament and sponsored by the Department of Transport (GOV.UK 2020a). HS2 Ltd employ Tier 1 contractors to design and build the railway through direct relationships, who in turn employ a plethora of consultants, subcontractors and others, cascading down to Tier 5. Archaeological organisations undertaking mitigation works along the route are employed as sub-contractors by Tier 1 (joint ventures of large civil engineering firms), during both the enabling and civil engineering stages of work. Most of the archaeological work has been packaged up and allocated to joint ventures or consortia, established by archaeological organisations to enable the provision of large, mobile teams and spread any financial risk of taking on a large contract. Their reception among field archaeologists has been mixed (Diggers' Forum 2020), although the job opportunities offered are significant.

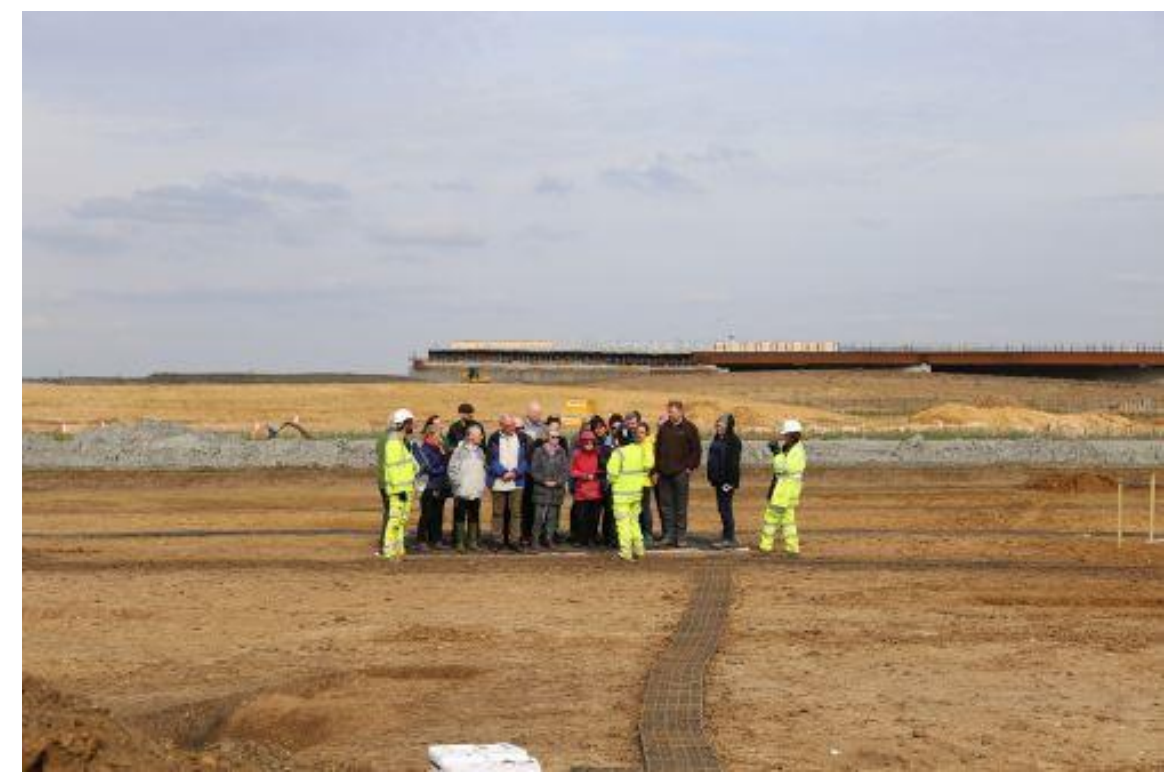

Figure 2: Open day on large-scale excavations on the A14, Cambridgeshire, England. Photo: A14CSH courtesy of MOLA Headland Infrastructure

Where the problems arise is with the loss of any flexibility in decision making and the hierarchical management structures. Coupled with an often negative public opinion of the HS2 project, this means that public access to the archaeology during work is controlled and restricted. However, the outward-facing aspects of the archaeology are designed and produced by the sub-contracting organisations and there have been some projects and events run by Wessex Archaeology and MOLA for example. There will undoubtedly be many successful aspects to this, and members of the public will be entertained and educated.

Ideally, however, the issue of fore-fronting public benefit in archaeological projects means a degree of input from the public themselves at early stages, to determine how they see the project developing, whether there are any local research aims that need to be considered in the project design, and to enable a collaborative approach that will remove the problem of the 'us and them' relationship often observed in public engagement, which is itself an assumption of passivity on the part of the public. There is an obvious danger with assumptions based on the need for the public to 'understand 
archaeology', inferring that a lack of understanding is somehow responsible for lack of participation, when in fact this leads us down a road of paternalistic assumptions about our relative status as keepers of this knowledge (Fredheim 2020) embedding the concept of exclusivity in the very space within which we need it to be eradicated.

\section{A Collaborative and Consultative Way Forward}

To ensure that our practice is inclusive in a meaningful way we should attempt to ascertain from the public their views on their heritage, at both local and national scales. It is difficult to see how we as archaeologists can fully understand what public benefit might be without consulting those we seek to provide benefit for, although this will be hugely challenging in practice. How this is undertaken is yet to be decided, particularly as there is an ethical obligation to engage with a wide variety of traditionally 'unengaged audiences'.

We know from a previous survey that some members of the UK public believe that heritage should be preserved using public funds, and used for education, entertainment and employment (Kadja et al. 2018, 100). Most had a positive view of archaeologists and believed they were undertaking scientific study (Kadja et al. 2018, 102). The UK respondents were aware that the funding results from the development control system, suggesting there is wider awareness than we usually perceive. Also of positive note was the support for excavation prior to development, with postponement of construction seen as important by a majority of respondents (Kadja et al. 2018, 104). There was also significant support for public involvement in decision making processes in their area (Kadja et al. 2018, 104), an idea that has not filtered down to UK planning policy or practice, but which we will be further investigating within the auspices of this UKRI project.

As with any public consultation, the questions asked and the manner in which they are framed is crucial. We should be willing to collaborate with audiences who have no interest at all in archaeology, but who instead could benefit through other allied provision of public benefit that might occur as an indirect result of funding for archaeology, for example urban design or public art. It will be crucial to acknowledge and listen to what we are told - we have become a conservative sector, but we need to open up to new ideas and approaches, and to be prepared to hear what the public have to say - even though it might be challenging to some of us.

\section{Archaeology and Construction: Interrogating the Relationship}

It would be positive if archaeologists and the public we seek to serve with our work took part in project design and implementation discussions at a much earlier stage and were able to communicate ambitions for better public benefit to the developers more effectively. In order to establish a process and programme for this the UKRI project will undertake some ethnographic research into the commercial and project-specific relationships between the construction industry and archaeologists. There will be 
challenges involved with this work, not least the client-contractor relationship which can be hard to see beyond, but it is intended that with the aid of a professional ethnographer this phase of work will highlight existing problems and opportunities with the current situation. The ethnographic study of participants themselves is not routinely undertaken in fieldwork, whether academic or commercial in scope. Previous studies (e.g.

Edgeworth 2006; Thorpe 2012) have highlighted the relevance of this to potential advancements within field practice and associated public benefit but there has not yet been the commitment to further this field of study in a more commercial sphere. This aspect of the project will offer the first opportunity to engage with the archaeologists and construction teams in a specific attempt to fully assess the capacity for better integrating our work into the wholesale churn of a development project and any potential barriers that might exist as a result of language, approach, behaviours and assumptions. From personal experience, if the message is successfully and strongly communicated through the construction team there will be adherence to its concepts on site, whereas if we as archaeologists are left to make the case for our role and archaeology, as is often the case, it becomes an unfair burden to place on an individual who can be faced with hostile reactions and made to feel generally unwelcome. This project is founded with the aim as much to ease that relationship on the ground as it is to influence policy at higher levels.

\section{Conclusions}

A career in field archaeology is an ambition for many and I am forever grateful to have been able to work on many exciting and challenging projects. I have tried to communicate these feelings to others and have felt a reciprocal excitement about what has been excavated. There remains a disconnect, however, between the public and the archaeology itself, which remain divided no matter how many village halls I fill. The passive concepts of 'presentation' or 'engagement' are no longer sufficient and as I get older I have been drawn to the idea that our very practice, its method and results should be incorporated into a more participatory approach. It is this that my project seeks to evolve through careful negotiation of the complex systems of development-led archaeology.

\section{Acknowledgements}

I would like to express my gratitude to the EAC for inviting me to be the Scientific Convenor for the Prague Symposium, and in particular to the President Barney Sloane and Executive Assistant Desislava Gradinarova. The Prague event was notable for the collegiate atmosphere and I would also like to thank the EAC members for a stimulating and enjoyable time. I would also like to thank my colleagues at MOLA, Kate Faccia, Harald Fredheim, Emma Dywer and Sara Perry for discussions round this article. Any errors or omissions are, of course, mine.

\section{Bibliography}


British Academy 2017 Reflections on

Archaeology. https://www.thebritishacademy.ac.uk/publications/reflections-

archaeology/ [Last accessed: March 2020]

ClfA 2020 Delivering Public Benefit from Archaeology. PDF [Last accessed: July 2020]

Crossick, G. and Kaszynska, P. 2016 Understanding the Value of Arts \& Culture: The AHRC Cultural Value Project, AHRC.

DEFRA 2020 'Natural Capital tool launched'. https://www.gov.uk/government/news/natural-capital-tool-launched-to-helpprotect-the-environment [Last accessed: July 2020]

DF (Diggers' Forum) 2020. 'An archaeologists' view of consortiums'. PDF [Last accessed: June 2020]

EAC 2019 Making the Case for Development-led archaeology. https://www.europaearchaeologiae-consilium.org/making-the-case-for-development-led [Last accessed: May 2020]

Edgeworth, M. (ed) 2006 Ethnographies of Archaeological Practice: Cultural Encounters, Material Transformations, Lanham and Oxford: AltaMira Press.

FAME 2020 The State of the Archaeological Market survey. PDF [Last accessed: July 2020]

Fredheim, L.H. 2020 'Decoupling "Open" and "Ethical" archaeologies: rethinking deficits and expertise for ethical public participation in archaeology and heritage', Norwegian Archaeological Review, https://doi.org/10.1080/00293652.2020.1738540

GOV.UK 2020a 'HS2: Who we are and what we do'. https://www.gov.uk/government/organisations/high-speed-two-limited [Last accessed: May 2020]

GOV.UK 2020b 'National Infrastructure and Construction Procurement Pipeline 202021'. https://www.gov.uk/government/publications/national-infrastructure-andconstruction-procurement-pipeline-202021 [Last accessed: July 2020]

GOV.UK 2021 'Valuing Culture and Heritage Capital: A framework towards decision making'. https://www.gov.uk/government/publications/valuing-culture-and-heritagecapital-a-framework-towards-decision-making

HM Treasury 2018 'The Green Book: central Government advice on appraisal and evaluation'. PDF [Last accessed: March 2020]

HM Treasury 2020 'The Magenta Book: central Government guidance on evaluation'. PDF [Last accessed: June 2020]

HS2 Ltd 2017. Historic Environment Research and Delivery Strategy: Phase One, HS2 Ltd. 
HS2 Ltd 2018 HS2 Archaeology. https://www.hs2.org.uk/building-hs2/archaeology/ [Last accessed: June 2020]

Kajda, K., Amala Marx, A., Wright, H., Richards, J., Marciniak, A., Rossenbach, K.S., Pawleta, M., Van Den Dries, M.H., Boom, K., Criado-Boado, M.P.G.F., Barreiro, D., Synnestvedt, A., Kotsakis, K., Kasvikis, K., Theodoroudi, E., Lüth, F., Issa, M. and Frase, I. 2018 'Archaeology, heritage, and social value: public perspectives on European archaeology', European Journal of Archaeology 21(1), 96117. https://doi.org/10.1017/eaa.2017.19

Leeds University 2020 'The Centre for Cultural Value'. https://ahc.leeds.ac.uk/centrecultural-value-1 [Last accessed: July 2020]

MOLA 2018 The Curtain Theatre. https://www.mola.org.uk/blog/curtain-theatre-citizensplayhouse-high-octane-drama [Last accessed: July 2020]

MOLA 2019 Archaeology and Public Benefit. https://www.mola.org.uk/archaeology-andpublic-benefit-ukri-future-leaders-fellowship [Last accessed: June 2020]

Pennington, A., Jones, R., Bagnall, A-M., South, J. and Corcoran, R. 2019 The impact of historic places and assets on community wellbeing - a scoping review, London: What Works Centre for Wellbeing. https://livrepository.liverpool.ac.uk/id/eprint/3034624

Reilly, S., Nolan, C. and Monckton, L. 2018 Wellbeing and the Historic Environment, Historic England https://historicengland.org.uk/images-books/publications/wellbeing-andthe-historic-environment/wellbeing-and-historic-environment/

Single, A. and Davies, L. 2021 Prehistory, Playhouses and the Public: London's Planning Archaeology, Internet Archaeology 57. https://doi.org/10.11141/ia.57.10

Thorpe, R. 2012 'Often fun, usually messy: fieldwork, recording and higher order of things' in H. Cobb, O. Harris, C. Jones, C. and P. Richardson (eds) Reconsidering Archaeological Fieldwork: Exploring On-Site Relationships Between Theory and Practice, New York: Springer. 31-52. https://doi.org/10.1007/978-1-4614-2338-6 3

Wills, J. 2018 'The world after PPG16: 21st century challenges for archaeology project report', ClfA and Historic England report. https://www.archaeologists.net/21st-centurychallenges-archaeology [Last accessed: July 2020] 